\title{
Impacts of foot-and-mouth disease on livelihoods in the Borena Plateau of Ethiopia
}

\author{
Tariku Jibat ${ }^{*}$, Berhanu Admassu², Tesfaye Rufael ${ }^{3}$, Maximilian PO Baumann ${ }^{4}$ and Carsten J Pötzsch ${ }^{5}$
}

* Correspondence:
jibattariku@gmail.com

${ }^{1}$ Faculty of Veterinary Medicine, Addis Ababa University, P.O. Box 34, Debre Zeit, Ethiopia

Full list of author information is available at the end of the article

\begin{abstract}
This study was conducted to estimate impacts of foot-and-mouth disease (FMD) on producers' livelihoods in Borena zone, southern Ethiopia, using participatory appraisal methods and secondary data sources. Livestock-related livelihood options accounted for $31 \%$ of the total means of food and income sources followed by crop farming. This study clearly showed that FMD had the greatest impact on the cattle-derived benefits. FMD outbreak frequencies were found to be significantly correlated to the length of extended dry season ( $r=0.377)$. In addition, FMD is ranked as the number one cattle disease after 1985 with significant rank change $(t=12.04)$ as compared to 1984 and before. Considering the impacts of FMD on peoples' livelihoods, FMD effective control strategies would reduce stress on people's lives, improve food security and keep social harmony.
\end{abstract}

Keywords: Foot-and-mouth disease, Participatory epidemiology, Socio-economics, Pastoralists, Ethiopia

\section{Background}

Foot-and-mouth disease (FMD) is a highly contagious viral disease of cloven-hoofed animals and is one of the most economically important diseases of livestock (Hughes et al. 2002). Because of the highly contagious nature of the virus and severity of economic impacts associated with the disease, FMD is the most important disease limiting the trade of animals and animal products throughout the world (Arzt et al. 2011a, b).

The most direct economic impact of FMD in endemic countries is the loss or reduced efficiency of production, which lowers farmers' income. The impact of reduced productivity of animals can be prolonged, and diseases can have lasting effects on livestock output in a number of 'hidden' ways such as delays in reproduction leading to fewer offspring, resulting in a reduced livestock population. At the local level, FMD reduces farmers' income and food availability for consumption.

At the national level, FMD slows economic growth by severely limiting trade opportunities (James and Rushton 2002). Heavy losses occur in small-scale mixed farming systems when outbreaks affect draught oxen during cropping season; FMD causes considerable losses of milk yield and weight among dairy and fattening stock, respectively. Milk is important in the diet of sub-Saharan pastoralists (Sadler et al. 2012). For example, for the Borena in southern Ethiopia and the Turkana in northwest Kenya, milk

(c) 2013 Jibat et al.; licensee Springer. This is an Open Access article distributed under the terms of the Creative Commons Attribution License (http://creativecommons.org/licenses/by/2.0), which permits unrestricted use, distribution, and reproduction in any medium, provided the original work is properly cited. 
accounts for $55 \%$ and $62 \%$ of their diet, respectively (Cossins and Upton 1987). At household level, milk is particularly an important food for pastoralists' children (Coppock 1994; Fielding et al. 2000).

FMD's role in contributing to the suffering and death of livestock, particularly when affected during periods of drought or at an early age by limiting their access to feed and water, can be significant. Furthermore, the FMD status of a country is an important determinant of international trade in livestock products, and the existence of FMD is an effective barrier from the markets with the highest prices for these products. It also causes significant losses in agriculture and tourism due to restriction on human movement (MOARD 2006).

FMD is characterized by fever, profuse salivation, vesicles in the mouth and on the feet and a drastic reduction in milk production; sudden death in young stock may occur (Radostits et al. 2006). A sequel to FMD frequently described in African cattle is the complex of clinical signs referred to as 'heat-intolerance syndrome' (HIS). The condition is characterized by intolerance to heat, and affected animals show pronounced panting, increased body temperature and pulse rate during hot weather, and abnormal hair growth (Catley et al. 2004; Barasa et al. 2008; Arzt et al. 2011a, b).

Seroprevalences for FMD virus-specific antibodies in pastoralist cattle of various ages were estimated as follows: 9\% in Orma herds in Kenya, 9.5\% in Maasai and Sukuma herds in Tanzania (Catley et al. 2004) and 15.8\% in South Sudan (Barasa et al. 2008). In Borena of Ethiopia, 21\% (Rufael et al. 2008) and 53.6\% (Mekonnen et al. 2011) seroprevalence was noted for the sub-types A, O, SAT 1, SAT 2 and SAT 3. There is no organized FMD control strategy in Ethiopia except sporadic cattle herd vaccination usually after outbreaks. In the Borena region FMD is a disease that is left without intervention and has been occurring with increasing frequency. The main objective of this study was to describe the livelihood of pastoralists in Borena zone and the impact of FMD and other cattle diseases on it.

\section{Study area}

The study was conducted in two districts of Borena zone, namely Arero and Miyo, in the southern part of Ethiopia from February to September 2011. The arid and semiarid agro-climatic characteristics of the region signify the importance of pastoralism as the most important source of livelihood.

The area is less endowed with moisture-retaining soil for crop-based livelihood, except for some places in the valley bottoms (Coppock 1994). The area is sparsely populated and is characterized by rain deficits, resulting in water shortages that reduce its livestock production potential. In addition to livestock's contribution to the overall food needs, it has a paramount importance in generating cash income for pastoral households. The Borena zone borders the Republic of Kenya to the south, the Somali Regional State to the east, the Southern Nation and Nationalities Regional State to the west and the Gujji Zone of Oromia Regional State to the north. The two districts were selected from the existing 13 districts of the zone based on the most recent FMD outbreak history and relative lack of studied information. From each selected district, five pastoral associations were randomly selected. From each pastoral association, about 12 to 15 people were selected for the participatory appraisal as 'informants/discussants' and 6 as key informants. 


\section{Methods}

A series of preparatory activities were undertaken before the study commenced. These involved a preliminary meeting held with local administration officials and participants to introduce and explain the objectives of the study emphasizing the livelihood impact and losses. The principles and methods of participatory appraisal described by Catley (2005) and Catley and Admassu (2003) were used to generate information on the livelihood impact of livestock diseases and the severity of FMD. The participatory appraisal methods used in the study included focus group discussion, semi-structured interview, simple scoring and pair-wise ranking, matrix scoring, proportional piling and seasonal calendar. The validity of the results was assured by triangulation (Catley 2005).

Simple and pair-wise ranking and comparisons were done by asking informant groups to list and rank cattle diseases that affect their herds, compare these diseases in pairs and decide which were the most important. These ranks were compared for significant differences across time. Matrix scoring was used to validate qualitatively herders' diagnosing ability to differentiate FMD from other cattle diseases based on clinical signs and indicators of the diseases. These were compared to FMD signs and indicators listed in reference textbooks like Radostits et al. (2006) and the Merck (2010). To assess the socio-economic benefits of keeping cattle and losses due to priority diseases, the diseases were represented by objects along the top of a matrix illustrated by line drawings on the ground. The socio-economic benefit indicators were also illustrated by the line drawings and placed along the $y$-axis. A pile of 100 stones representing ' $100 \%$ benefit from cattle' were divided into different benefits in healthy cattle. Then, the benefit lost due to each disease was reduced from each benefit allocated to represent the relative reduction in benefit due to disease (Catley and Mohammed 1996; Barasa et al. 2008). Proportional piling was used to gather information on livelihood means, sources of food, new disease cases and benefits derived during the past one year from cattle both with FMD and HIS.

Each group discussant was asked to remember key natural, social, economic and political events related to FMD outbreaks, long dry seasons, drought and tribal conflicts. Time periods were identified based on the Gada administration system of the Borena, i.e. Jaldessa liben (1960 to 1967), Goba Bule (1968 to 1975), Jilo Agaa (1976 to 1983), Boru Guyo (1984 to 1991) Boru Medha (1992 to 1999) and Liben Jeldessa (2000 to 2007). Each of these periods was rated for an FMD outbreak affecting the majority of susceptible and unvaccinated cattle in the area, length of long dry season, drought severity, as well as inter-clan and tribal conflict numbers and severity ranking from 1 to 4 .

The responses related to climate were triangulated with unpublished data from the National Meteorology Agency of Ethiopia. The seasonal calendar technique was used to describe seasonal variations in the amount of rainfall, new FMD cases, calving season, cattle contact with wildlife and livelihood indicators such as milk availability, grain purchase, cattle movement and trade, and socio-cultural practices related to cattle.

The data collected were entered into a Microsoft Excel 2007 spreadsheet and analyzed using SPSS version 18 for descriptive statistics, Kendall's coefficient of concordance $(W)$ and the independent $t$-test for correlations of different variables with FMD occurrence and comparison of disease ranks. The level of agreement among the scores of informant groups was assessed using Kendall's coefficient of concordance (W) (Siegel 
and Castellan 1994). Consequently, evidence of agreement between informant groups was categorized as 'weak', 'moderate' and 'strong' according to published guidelines on the interpretation of $W$ and the $P$ values assigned; agreement was termed 'weak' for $W<0.26, P>0.05$; 'moderate' for $W=0.26$ to $0.38, P<0.05$ and 'strong' for $W>0.38$, $P<0.01$. The Pearson correlation coefficient was used to establish quantitatively the relationship between FMD outbreaks and the variables long dry season, drought and conflict.

\section{Results}

\section{Livelihood options and food sources for the Borena people}

Livestock-related livelihood options accounted for about 32\% of the total means of food, social and economic contributions, whereas farming, food aid and petty trade contributed $21 \%, 15 \%$ and $14 \%$, respectively. In addition, mining, charcoal production and employment are also mentioned as means of living. Food sources analysis showed the contribution of livestock as the main source of food to households. Likewise, the most important food items consumed at household level are milk and butter accounting for $42 \%$, grain $35 \%$, meat $10 \%$, vegetables and fruits $4 \%$ and others $9 \%$ (Figures 1 and 2).

\section{Disease characterization by clinical signs}

Based on simple and pair-wise ranking, six major cattle diseases and adverse conditions, i.e. FMD, contagious bovine pleuropneumonia, pasteurellosis, tick infestation, blackleg and HIS after FMD were identified. Strong agreement ( $W=0.58$ to $0.94, P=$ 0.000 ) was observed among the informant groups for all disease indicators. All informant groups recognized FMD and HIS as the sequel of FMD as different cattle diseases called locally 'Hoyalee and 'Gaandilee, respectively. According to informants, the clinical signs and indicators of FMD were 'kissing sound', salivation, lameness/'footsore', mouth lesions and contagiousity whereas hair 'overgrowth', seeking shade and 'panting' are signs or indicators of HIS (after FMD) (Table 1). The allocation of different scores for FMD and HIS showed a clear understanding of the respective clinical signs.

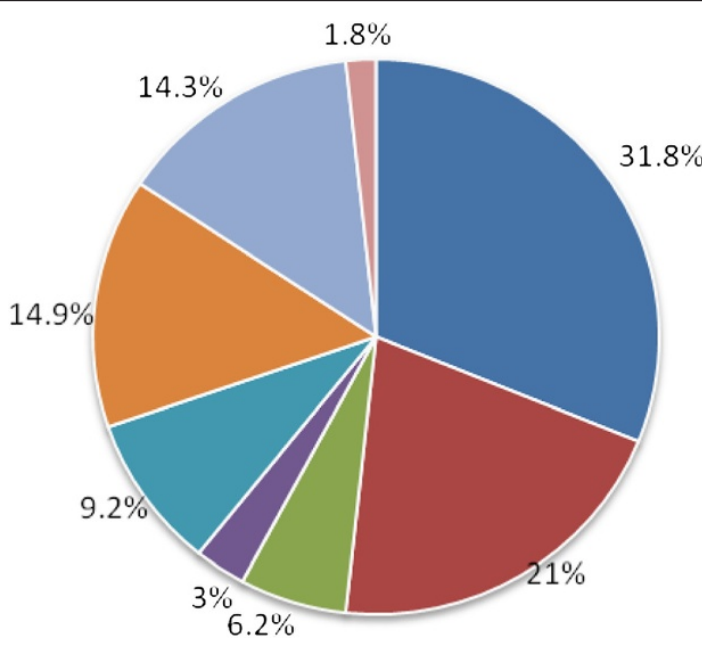

- Rearing livestock

- Crop farming

Mining

- Charcoal selling

- Employment

- Petty trade

- Food aid

Others

Figure 1 Livelihood options for the Borena people. 


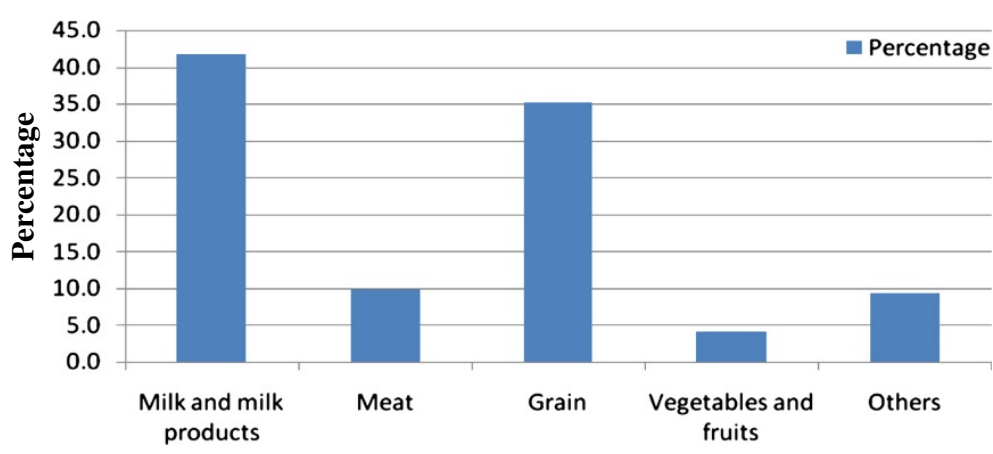

Food items

Figure 2 Relative importance of food consumed by the Borena people.

\section{Benefits lost due to major cattle diseases}

As shown in Figure 3, the overall benefit of cattle, cattle products and other benefits to pastoralists' livelihoods referred to as 'basic contribution' was reduced as a result of major cattle diseases. Unlike for other endemic conditions like pasteurellosis and tick infestation, FMD- and HIS-diseased cattle are not used for any social and cultural purposes like bride price that contributes $21 \%$ to the basic contribution/benefits of cattle. This represents the most important single impact of FMD on cattle-derived benefits; the opportunities for social and cultural practices are almost entirely lost when FMD outbreaks occur.

\section{Seasonal calendar}

The seasonal calendar exercise (Figure 4) demonstrated the variations in the amount of rainfall, new cases of FMD and other livelihood variables like grain and milk availability over the seasons of the year. Four distinct seasons were identified, namely Bonahagayaa, the long dry season from December to February; Ganna, the long rainy season from March to May; Adollessa, the short dry season from June to August and Hagayya, the short rainy season from September to November. Socio-cultural practices related to cattle, cattle trade and movement in search of pasture and water reach their highest peak in the short dry season followed by the long dry season which coincides with the highest numbers of new FMD cases during the year. The seasonal new FMD cases curve showed a reciprocal pattern compared to the seasonal amount of rainfall but no obvious correlation with the cattle-wildlife contact apparently being constant throughout the year. The proportion of milk availability was found to follow a similar pattern as the rainfall, but has inverse relationship to the occurrence of new FMD cases and the proportions of cattle movements, trade and calving season.

\section{Ranking of cattle diseases}

A comparison of ranks for the most important cattle diseases after 1985 is summarized in Table 2. The informants indicated that FMD is a disease that is well known to them and has been occurring with increasing frequency in their herds.

Table 3 demonstrates that the FMD outbreak occurrence frequency was found to be significantly correlated to the length of extended dry season (correlation coefficient $r=$ 
Table 1 Summarized matrix scoring (range in brackets) of major clinical signs of cattle diseases with Kendal's coefficient of concordance (W) for the median scores

\begin{tabular}{|c|c|c|c|c|c|c|c|}
\hline Indicators/clinical signs & $W^{P \text { values }}$ & $\begin{array}{l}\text { Foot-and-mouth } \\
\text { disease }\end{array}$ & $\begin{array}{l}\text { Heat-intolerance } \\
\text { syndrome }\end{array}$ & $\begin{array}{l}\text { Contagious bovine } \\
\text { pleuropneumonia }\end{array}$ & Pasteurellosis & Tick infestation & Blackleg \\
\hline Mortality & $0.865^{*}$ & $1(0,2)$ & $0(0,1)$ & $7(6,9)$ & $6(6,9)$ & $1(0,4)$ & $9(3,10)$ \\
\hline Milk reduction & $0.783^{*}$ & $7(5,10)$ & $6(4,8)$ & $4(0,5)$ & $4(3,5)$ & $2(0,3)$ & $4(1,4)$ \\
\hline Lameness/footsore & $0.769^{*}$ & $16(10,20)$ & $0(0,6)$ & $1(0,3)$ & $0(0,0)$ & $3(0,10)$ & $5(3,9)$ \\
\hline Nasal discharge & $0.904^{*}$ & $0(0,2)$ & $0(0,0)$ & $6(3,14)$ & $18(14,20)$ & $0(0,4)$ & $0(0,0)$ \\
\hline Abortion & $0.768^{*}$ & $12(5,20)$ & $6(2,10)$ & $2(0,6)$ & $1(0,5)$ & $2(0,5)$ & $1(0,2)$ \\
\hline Seeking shade & $0.809^{*}$ & $2(0,5)$ & $19(10,20)$ & $2(0,5)$ & $2(0,5)$ & $0(0,0)$ & $0(0,0)$ \\
\hline Hair overgrowth & $0.821^{*}$ & $0(0,5)$ & $25(20,25)$ & $0(0,2)$ & $0(0,0)$ & $0(0,0)$ & $0(0,0)$ \\
\hline Sudden death & $0.943^{*}$ & $0(0,1)$ & $0(0,0)$ & $4(3,7)$ & $5(3,8)$ & $1(0,2)$ & $15(8,16)$ \\
\hline Salivation & $0.783^{*}$ & $18(12,25)$ & $0(0,3)$ & $2(0,4)$ & $4(0,9)$ & $0(0,5)$ & $0(0,2)$ \\
\hline Mouth lesion & $0.883^{*}$ & $20(6,25)$ & $0(0,8)$ & $0(0,0)$ & $0(0,0)$ & $0(0,0)$ & $0(0,0)$ \\
\hline Kissing sound & $0.788^{*}$ & $23(18,25)$ & $0(0,2)$ & $0(0,5)$ & $0(0,6)$ & $0(0,0)$ & $0(0,0)$ \\
\hline Panting & $0.806^{*}$ & $5(2,6)$ & $13(12,20)$ & $5(2,8)$ & $1(0,3)$ & $0(0,2)$ & $0(0,4)$ \\
\hline Morbidity & $0.699^{*}$ & $10(2,15)$ & $1(0,2)$ & $5(2,8)$ & $5(2,7)$ & $2(2,5)$ & $2(1,8)$ \\
\hline Contagiousity & $0.841^{*}$ & $12(10,14)$ & $1(0,4)$ & $5(3,10)$ & $4(3,5)$ & $2(1,3)$ & $2(0,3)$ \\
\hline Emaciation & $0.581^{*}$ & $10(4,10)$ & $5(0,8)$ & $5(0,7)$ & $3(0,5)$ & $6(2,7)$ & $0(0,2)$ \\
\hline
\end{tabular}




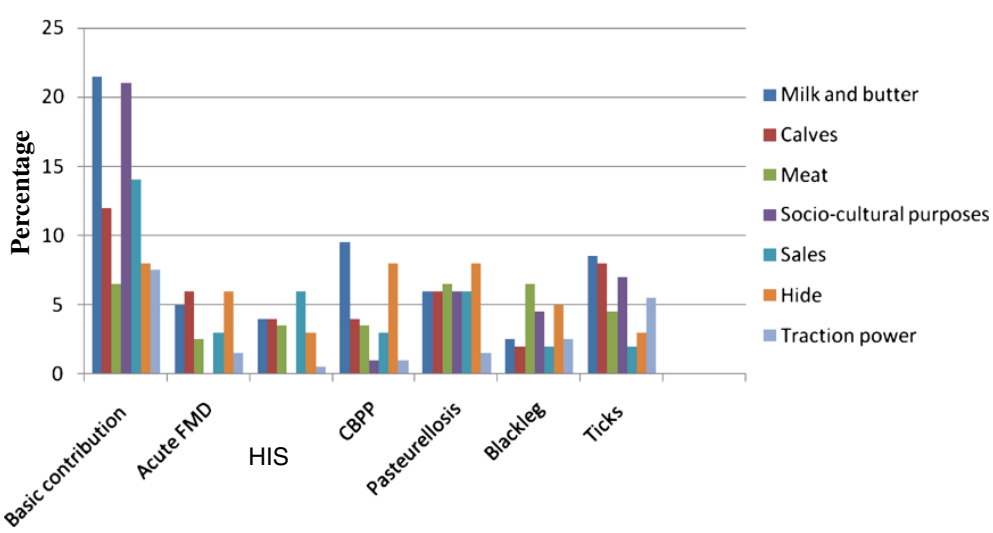

Figure 3 Benefits of cattle to livelihoods of pastoralists and benefit losses due to major cattle diseases.

$0.377)$ and with occurrence of clan and tribal conflicts $(r=0.261)$, but no correlation was found with drought.

\section{Discussion}

This study indicates that livestock contributes $32 \%$ to the livelihood means as a source of food, income and for other socio-economic purposes. Milk and milk products contribute $41.6 \%$ to the household food. This result is in agreement with a similar study by Cossins and Upton (1987) which reports that milk accounts for $55.4 \%$ of the diet of the Borena people. According to Fielding et al. (2000), at household level, milk was particularly an important food for pastoralists' children. The seasonality of food availability severely compromises the nutritional status and affects child growth and life expectancy. FMD is known to reduce milk production and can aggravate milk shortage as it predominantly occurs during dry seasons, hence exposing particularly the children and older people of pastoralists to malnutrition. Adults can better withstand shortages of animal products by using crop-derived food as a substitute (Barasa et al. 2008).

As this study was conducted during the extended long dry season, Bona-hagayaa, when there was no crop cultivation, it was difficult to assess the impact of FMD on traction power. However, in recent years crop cultivation has increased in the Borena

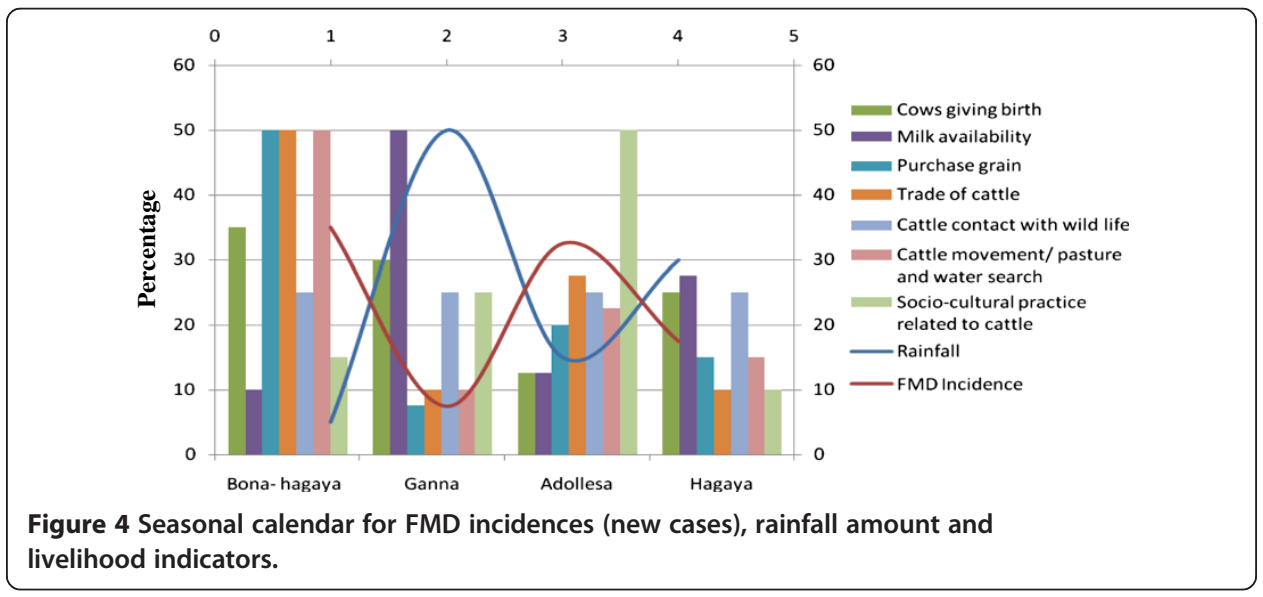


area where oxen are used to plough and harvest crops (Solomon et al. 2007). Since one of the manifestations of FMD is lameness, cattle lose their ability for hard work when affected by FMD (Radostits et al. 2006); this would translate into food insecurity and socio-economic problems. A study done by Bayissa et al. (2011) in the Borena region reveals that FMD-affected oxen do not plough for one entire crop season. Additionally, oxen affected by HIS are not used for ploughing any longer.

The clinical signs described for FMD and HIS are consistent with clinical signs and indicators described in veterinary literature and textbooks (Merck 2010; Radostits et al. 2006). The good diagnostic skills of pastoralists were also confirmed by FMD serology as done by Rufael et al. (2008) who demonstrated that pastoralists can diagnose FMD with a positive predictive value of $93.1 \%$. The average benefit lost due to FMD and HIS is higher than all other major cattle diseases studied.

The Borena people's life is highly linked to social and cultural practices like Jila titling child name, 'marriage' bride price and Busa Gonofa where the clans assist their members with animals in case one lost livestock to natural disaster or raids; it also involves slaughtering animals for someone who is injured or has broken bones. It is known that livestock plays a very important role in the Borena community, in terms of social and kinship ties. Thus, FMD disturbs the social harmony of Borena communities as cattle affected by FMD and HIS are not used for social and cultural purposes like bride prices or fines for dispute settlement.

According to the results from the seasonal calendar, FMD outbreaks occur mostly in the dry season when pasture is dry and reduced, water is scarce and the ground is very hard for cattle with foot lesions to move. Severely affected cattle become recumbent and lose body condition rapidly, and consequently, milk is least available for consumption. Outbreaks of FMD during this time can inflict severe stress on household food security due to its effects on milk production. During the long dry season, cattle movement peaks due to cattle trade and migration in search of pasture and water. This movement pattern is believed to be partly responsible for the introduction and spread of FMD.

According to the findings of this study, rinderpest was the most important disease before 1984, based on its impacts, but it was none of the major diseases after 1985 as it was controlled and later eradicated and declared by OIE in 2010 (OIE 2011). FMD replaced rinderpest in the rank as the number one cattle disease after 1985, indicating that FMD is a disease that is left without intervention and has been occurring with increasing frequency in the Borena region. The increased number of new FMD cases may be due to longer dry seasons when more movement and mixing of livestock

Table 2 Ranking of FMD and other major cattle diseases (rank 1 most important to 4 least important)

\begin{tabular}{lcccc}
\hline Disease & $\mathbf{1 9 8 5}$ and after & $\boldsymbol{t}$ value & $\boldsymbol{P}$ value & - \\
\hline Rinderpest & - & - & 0.18 & - \\
Contagious bovine pleuropneumonia & 2.4 & 1.41 & 0.35 \\
Blackleg & 4.5 & -2.29 & 0.03 & 0.52 \\
Pasteurellosis & 4.0 & -0.71 & 0.49 & 0.42 \\
Trypanosomosis & 4.2 & 1.43 & 0.17 & 0.91 \\
Foot-and-mouth disease & 1.2 & 1.43 & 0.00 & 0.36 \\
\hline
\end{tabular}


Table 3 Correlation between FMD occurrence and factors impeding cattle husbandry

\begin{tabular}{llcccc}
\hline & & & \multicolumn{3}{c}{ Occurrence of: } \\
\cline { 3 - 5 } FMD outbreaks & FMD outbreaks & Drought & Long dry season & Conflict \\
\cline { 3 - 5 } Drought & $P$ value & 1 & 0.205 & $0.568^{*}$ & 0.239 \\
& Pearson correlation & 0.169 & 1 & 0 & 0.046 \\
\multirow{2}{*}{ Long dry season } & $P$ value & 0.161 & & $0.559^{*}$ & -0.068 \\
& Pearson correlation & 0.377 & & 0 & 0.578 \\
Conflict & $P$ value & 0.001 & & 1 & 0.157 \\
& Pearson correlation & 0.261 & & & 0.193 \\
& $P$ value & 0.029 & & & 1 \\
\hline
\end{tabular}

*Significantly correlated.

occurs; other factors like larger cattle and human populations might be a factor, although there is no statistical evidence of how animal and human demographics have changed over the above-mentioned period.

In the Borena pastoral area, FMD outbreaks are known to occur two to three times per year, especially during the dry period when cattle have to move long distance in search of pasture and water, possibly leading to immunosuppression resulting in higher disease susceptibility as well as to increased animal contact rates. Conflicts between clans and ethnic groups in the pastoral areas of Ethiopia additionally impede livestock husbandry and health management as the conflicts hamper access of cattle to water and grazing land resources and territories (Grimble and Wellard 1997; Conroy et al. 1998).

FMD in pastoral areas is perceived as unavoidable by pastoralists due to its endemic occurrence. For decision-makers, FMD is a minor disease due to the low productivity of pastoral herds as compared to commercial or semi-commercial dairy units. However, this study confirms the findings of Rufael et al. (2008) that pastoralists suffer severely from the impact of FMD.

\section{Conclusion}

The study has shown that FMD causes losses associated with reduced animal production and affects the social as well as economic well-being of the Borena pastoralists. Further to this research, more data are necessary to assess the spatial and temporal distribution of FMD and to develop FMD control strategies that benefit the pastoralists in Ethiopia.

The limitations and shortcoming of this study could be biases and inaccuracies which resulted from the methodology of participatory appraisals, the short study time and the limited availability of data on the impacts of FMD. However, several other research studies with pastoralists in sub-Saharan Africa have shown that they have a significant recalling ability of past events, especially in relation to their animals (Catley and Admassu 2003; Catley 2005). 


\section{Authors' contributions}

TJ was involved in the data collection, analysis, interpretation and write up. BA, TR, MPOB and CJP generated the research idea, validated the data, approved the analysis and rectified the final paper for publication. All authors have read and approved the final version.

\section{Authors' information}

TJ is a specialist in Trans-boundary animal diseases epidemiology and economics currently working for Addis Ababa University Faculty of Veterinary Medicine in Ethiopia, BA works as a senior researcher at Tufts University Feinstein International Center. TR is an epidemiologist at Ethiopian National Animal Health Diagnostics and Investigation Center. MPOB is a staff member at the Faculty of Veterinary Medicine, Freie Universität Berlin. CJP is a consultant veterinary epidemiologist in Germany.

\section{Acknowledgements}

This study was carried out within the Joint Master in Transboundary Animal Disease Management (MTADM) Programme partially funded by the ACP-EU Cooperation Programme in Higher Education EDULINK. The scholarship to attend the Joint MTADM Course was provided by DAAD (Deutscher Akademischer Austauschdienst). The authors also would like to thank Tufts University Feinstein International Center in Addis Ababa Regional Office, Dr. A. Catley, Dr. M. Barasa, Dr. Dawit Abebe and the Borena people for their contribution to the study.

\section{Author details}

${ }^{1}$ Faculty of Veterinary Medicine, Addis Ababa University, P.O. Box 34, Debre Zeit, Ethiopia. ${ }^{2}$ Feinstein International Center, Tufts University, P.O. Box 1078, Addis Ababa, Ethiopia. ${ }^{3}$ National Animal Health Diagnostics and Investigation Center, P.O. Box 34, Sebeta, Ethiopia. ${ }^{4}$ Faculty of Veterinary Medicine, Freie Universität Berlin, Königsweg 67, Berlin 14163, Germany. ${ }^{5}$ EpiVetGermany, Fontanestr. 12, Tramnitz 16866, Germany.

Received: 4 May 2012 Accepted: 8 January 2013

Published: 14 June 2013

\section{References}

Arzt, J, B Baxt, MJ Grubman, T Jackson, N Juleff, J Rhyan, E Rieder, R Waters, and LL Rodriguez. 2011a. The pathogenesis of foot-and-mouth disease II: Viral pathways in swine, small ruminants, and wild life; myotropism, chronic syndromes, and molecular virus-host interactions. Transboundary and Emerging Diseases 58(2011): 305-326.

Arzt, J, N Juleff, Z Zhang, and L Rodriguez. $2011 \mathrm{~b}$. The pathogenesis of foot-and-mouth disease I: Viral pathways in cattle. A review. Transboundary and Emerging Diseases 58(4): 291-304. doi:10.1111/j.1865-1682.2011.01204.X.

Barasa, M, A Catley, D Machuchu, H Laqua, E Puot, TD Kot, and D Ikiror. 2008. Foot-and-mouth disease vaccination in south Sudan: Benefit-cost analysis and livelihoods impact. Transboundary and Emerging Diseases 55: 339-351.

Bayissa, B, G Ayelet, M Kyule, Y Jibril, and E Gelaye. 2011. Study on seroprevalence, risk factors, and economic impact of foot-and-mouth disease in Borena pastoral and agro-pastoral system, southern Ethiopia. Tropical Animal Health and Production 43(4): 759-766.

Catley, A. 2005. Participatory epidemiology: A guide for trainers. Nairobi: African Union/Interafrican Bureau for Animal Resources.

Catley, A, and B Admassu. 2003. Using participatory epidemiology to assess the impact of livestock diseases. FAO-OIE -AU/BAR-IAEA consultative group meeting on contagious bovine pleuropneumonia in Africa, 12-14 November 2003. Rome: FAO Headquarters.

Catley, A, and A Mohammed. 1996. The use of livestock-disease scoring by a primary animal-health project in Somaliland. Preventive Veterinary Medicine 28: 175-186.

Catley, A, RT Chibunda, E Ranga, S Makungu, FT Magayane, G Magoma, MJ Madege, and W Vosloo. 2004. Participatory diagnosis of a heat-intolerance syndrome in cattle in Tanzania and association with foot-and-mouth disease. Preventive Veterinary Medicine 65: 17-30.

Conroy, C, A Rai, N Singh, and MK Chan. 1998. Conflicts affecting participatory forest management: Some experiences from Orissa. Revised version of a paper presented at the workshop on participatory natural resource management in developing countries, Oxford, UK, 6-7 April 1998.

Coppock, D. 1994. The Borena plateau of southern Ethiopia: Synthesis of pastoral research development and change, 1980-1991. Addis Ababa: International Livestock Research Institute.

Cossins, N, and M Upton. 1987. The Borena pastoral system of Southern Ethiopia. Agricultural Systems 25(3): 199-218.

Fielding, W, C Gullick, P Coutts, and B Sharp. 2000. An introduction to the food economy research in Southern Sudan 1994-2000. Nairobi: World Food Program and Save the Children UK.

Grimble, R, and K Wellard. 1997. Stakeholder methodologies in natural resource management: A review of principles, contexts, experience and opportunities. Agricultural Systems 55: 173-193.

Hughes, G, V Mioulet, R Kitching, M Woolhouse, S Andersen, and A Donaldson. 2002. Foot-and-mouth disease virus infection of sheep: Implications for diagnosis and control. The Veterinary Record 150: 724-727.

James, A, and J Rushton. 2002. The economics of foot and mouth disease. Office International des Épizooties (OIE) Scientific and Technical Review 21(3): 637-644.

Mekonnen, H, D Beyene, T Rufael, A Feyisa, and F Abunna. 2011. Study on the prevalence of Foot and Mouth Disease in Borana and Guji zones, southern Ethiopia. Veterinary World 4(7): 293-296.

Merck. 2010. Merck veterinary manual, 10th ed. Whitehouse Station: Merck Publishing.

Ministry of Agriculture and Rural Development (MOARD). 2006. Foot and Mouth Disease control plan. Addis Ababa: MOARD.

Office International des Épizooties (OIE). 2011. Rinderpest eradication. Office International des Épizooties Bulletin No. 2011-2. Paris: OIE. 
Radostits, O, C Gay, K Hinchcliff, and P Constable. 2006. Veterinary medicine, a textbook of the diseases of cattle, sheep, goats, pigs and horses, 10th ed, 1223-1231. London: Bailliere Tindal.

Rufael, T, A Catley, A Bogale, M Sahle, and A Shiferaw. 2008. Foot and mouth disease in the Borana pastoral system, southern Ethiopia and implications for livelihoods and international trade. Tropical Animal Health and Production 40: 29-38.

Sadler, K, E Mitchard, A Abdi, Y Shiferaw, G Bekele, and A Catley. 2012. Milk matters: The impact of dry season livestock support on milk supply and child nutrition in Somali Region, Ethiopia. Addis Ababa: Feinstein International Center, Tufts University and Save the Children.

Siegel, S, and NJ Castellan. 1994. Nonparametric statistics for the behavioral sciences, 2nd ed. New York: McGraw-Hill. Solomon, T, H Snyman, and G Smit. 2007. Cattle-rangeland management practices and perceptions of pastoralists towards rangeland degradation in the Borana zone of southern Ethiopia. Journal of Environmental Management 82: 481-494.

doi:10.1186/2041-7136-3-5

Cite this article as: Jibat et al: Impacts of foot-and-mouth disease on livelihoods in the Borena Plateau of Ethiopia. Pastoralism: Research, Policy and Practice 2013 3:5.

\section{Submit your manuscript to a SpringerOpen ${ }^{\circ}$ journal and benefit from:}

- Convenient online submission

- Rigorous peer review

- Immediate publication on acceptance

- Open access: articles freely available online

- High visibility within the field

Retaining the copyright to your article

Submit your next manuscript at $\gg$ springeropen.com 